The Hornhautmesser (Augenarztliche Operationslehre 1922: 525 : Fig. 447) is an angled knife, with a blunt point and two lateral edges. The English reproduction (Fig. 18a) is by Down Bros.

Had any ungraspable Descemet tags remained attached to the edge of the trephine bed, they would have been divided against the " niblick" by a tiny gouge-shaped instrument (Franceschetti's) equivalent to about $\frac{1}{8}$ of the diameter of a $5 \mathrm{~mm}$. corneal trephine (Fig. 19).

Strands of Descemet's membrane rarely remain attached to the graft itself, but if they do highly curved scissors are to be preferred to the instruments above, as the pressure or traction necessary for their use might damage it. Though the cutting action of instruments for removing these strands varies greatly it should be noted that the most successful have a common feature-a curved cutting edge concentric with or of smaller arc than the trephine hole.

The graft was. lifted out of the holofusine on its little "strainer," pushed on to the back of a metal lid spatula repositor, and from there to its bed by an iris repositor. The sutures were tied, argyrol inserted and the eyes double-padded. Time about 25 minutes.

Among the instruments in reserve were Arruga's forceps, which can be employed to put sutures directly through the graft edge at two points if there is a vitreous loss.

It is difficult to convey in a bald account of the technique the smoothness and absolute confidence of the whole procedure.

\title{
RETINAL ARTERY OCCLUSION \\ A Report Illustrating the Pathogenesis of the Fundal Appearances and the effect of Acetyl-choline*
}

BY

\section{C. Michaelson \\ GLASGOW}

THE following case is described because it illustrates :-

(1). The rôle of spasm in arterial occlusion and the effect of acetyl-choline ;

(2). A relationship between arterial spasm and anatomical changes in the vessel wall;

(3). The nature of the retinal opacity with the influence of the capillary distribution in determining its extent.

* Received for publication, August 9, 1947. 
The female patient, aged 41 years, was first examined on April 22, 1947. She then stated that the vision of the left eye had been defective since April 16 and that she had had headaches for several days following the onset of the visual defect. The vision of the left eye had previously been as good as that of the right.

On examination the right eye was found to be normal and to have a visual acuity of $6 / 9$ with $+4: 50 \mathrm{D}$. sph. $+1.50 \mathrm{D}$. cyl. $90^{\circ}$. The retinal vessels were free from any abnormality. The vision of the left eye was reduced to counting of fingers at about one metre. The pupil was slightly larger than that of the right eye, but reacted to light. The media were clear but the fundus showed a large triangular area of white opacity in the retina situated in relationship to the macular. branch of the inferior temporal artery, as indicated in Fig. 1. The junction of the inferior temporal artery and its macular branch was obscured by a bright linear reflex. The white retinal opacity was very sharply defined below and above by the inferior temporal vein and its macular branch respectively. One very striking feature was that the affected branch of the inferior temporal artery was venous in colour where it became discernable beyond the retinal opacity. The rest of the fundus was normal and the retinal vessels showed no unusual features.

The diagnosis of occlusion of the macular branch of the inferior temporal artery was made and the patient was admitted to hospital. At 7.45 p.m. that evening the condition of the fundus remained as already noted and $0.1 \mathrm{gm}$. of acetyl-choline was injected retrobulbarly, atropine having been previously instilled into the eye. Fifteen minutes following injection the white opacity in the retina was noted to be markedly diminished and to be confined almost entirely to the area between the affected artery and macular vein. One hour later the condition was very much the same. The following day there was noticed no further change in the retinal opacity but the occluded artery at its junction with the inferior temporal artery could be seen for first time. It had a well developed central light streak. Fig. 2 shows the appearance of the fundus on the day following treatment with acetyl-choline. During the next few days the retinal opacity disappeared completely. Thirteen days after the onset of the occlusion and seven days after its relief with acetylcholine a faint sheathing was noticed for the first time at the site of the spasm. It gradually became more apparent and Fig. 3 indicates its appearance on June 5. There was little visual improvement to parallel the ophthalmoscopic changes, but when last examined she could see the lower part of the letters of 6/24 line on Snellen's chart with +4:50 D. sph. and +1.0 D. cyl. There was no peripheral field defect using a $2 / 300$ white object but there was a loss of the upper field to a $2 / 2000$ white object on the Bjerrum 


\section{Retinal. Artery Occlusion}

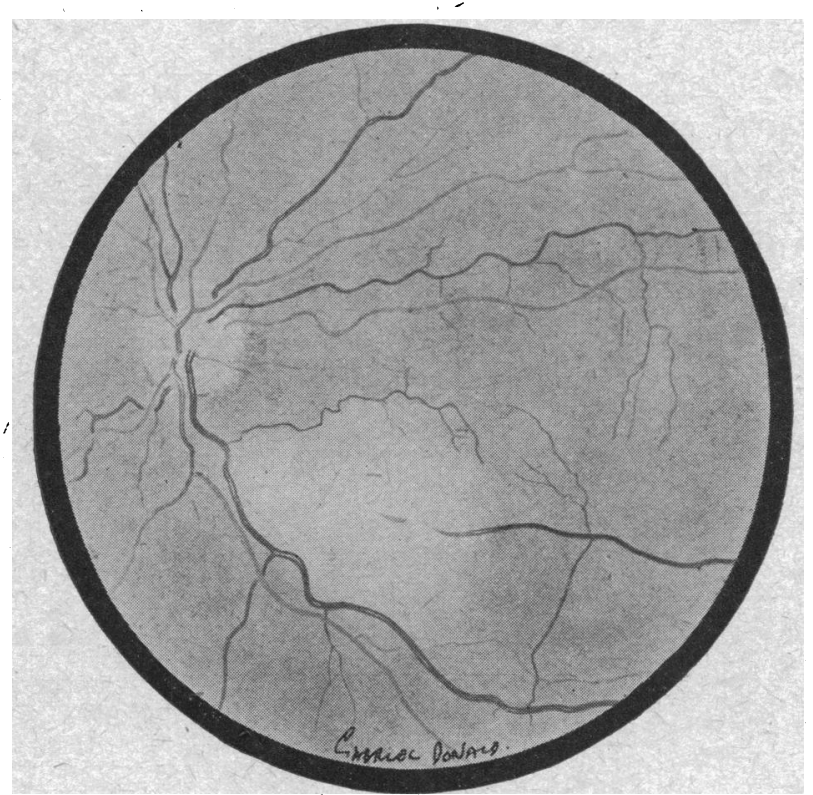

FIG. 1.

Appearance of fundus on April 22, 1947, showing the area of white retinal opacity sharply defined below by the inferior temporal vein and above by its macular branch.

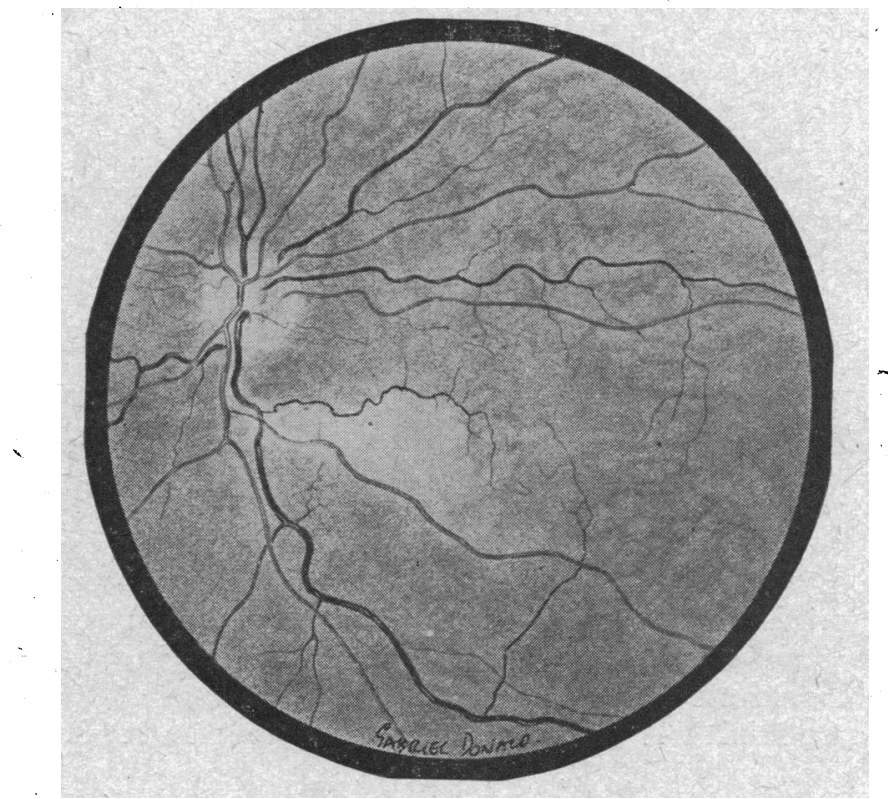

FIG. 2.

Appearance of fundus on day following treatment. The area of opacity is markedly diminished and confined almost entirely to area between affected artery and the macular vein. Note that the affected artery has now resumed its arterial colour. 
screen (see chart). A general examination was carried out by Dr. L. Scott. The blood pressure was found to be $120 \mathrm{~mm}$. Hg systolic and $70 \mathrm{~mm}$. $\mathrm{Hg}$ diastolic. Apart from a low haemoglobin estimate (64 per cent.). no abnormality was found. She gave an indefinite history of headaches which, however, do not appear to have been of the migrainous type.

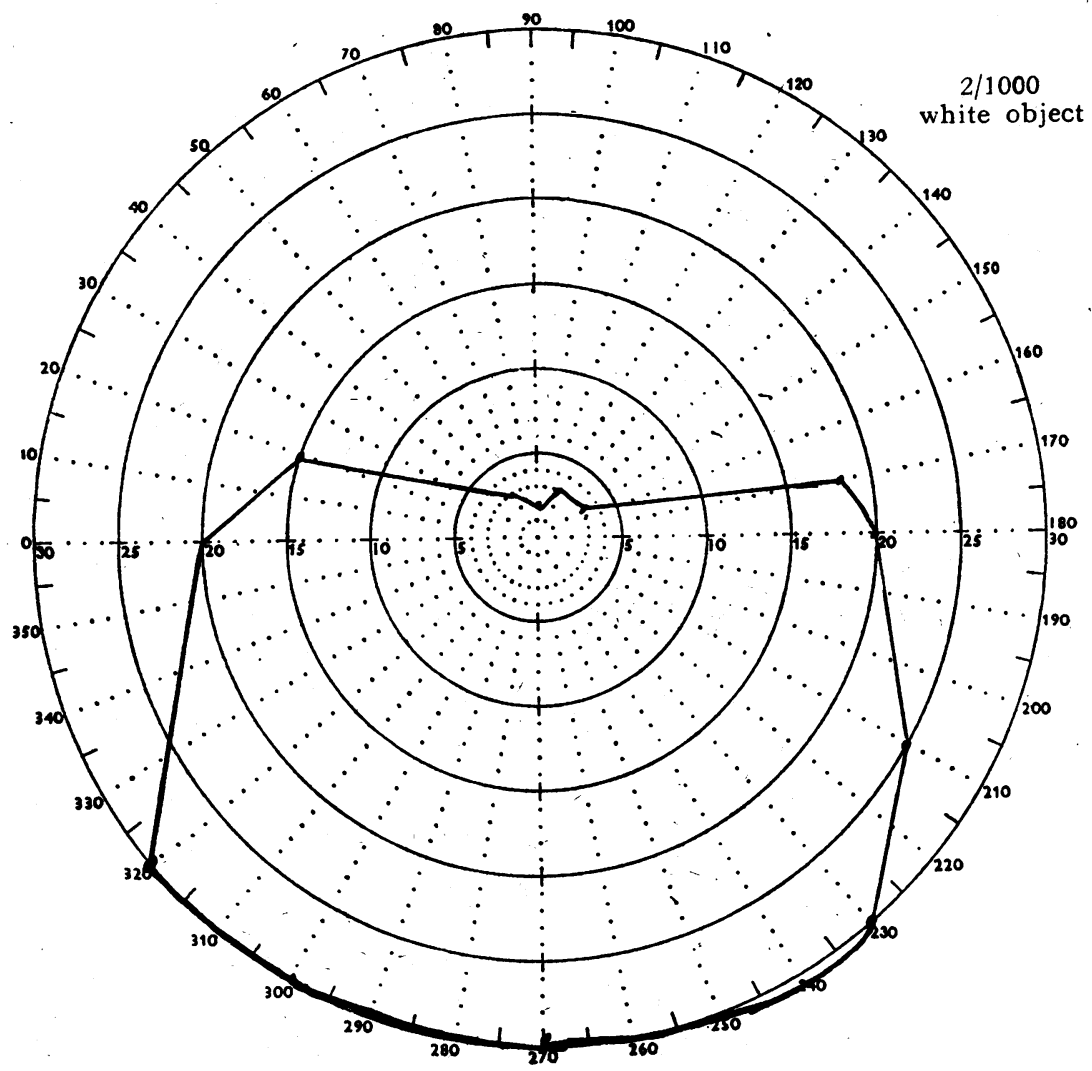

Since Raynaud's observations in 1874, angiospasm has been repeatedly observed to be the cause of arterial occlusion in the retina. Apart from the elderly with hypertension and arterio-sclerosis the condition occurs in young or middle-aged individuals who may show other evidences of vascular irritability such as epilepsy or migraine. or in whom may be present vascular sensitivity to various factors, such as toxins from influenza, malaria, or pregnancy (Mylius 1928, Sedan 1929, Griffith 1931, Davenport 1931, Freeman 1933, Selinger 1937, and Schousboe 1937),

Arterial angiospasm máy occur in young people who otherwise 


\section{MOGAg}

Retinal ARtery OCcLusion

have no evidence of vascular irritability. (Ormond 1918, Traquair 1933).

The present case belongs to this last group. The localised sheathing was not present until the seventh day following the relief of the spasm and its development to the stage noted in Fig. 3 was reached 43 days after the onset of the occlusion. The spasm had apparently occasioned the sheathing which, with the local narrowing of the blood column, probably indicates intimal proliferation and degeneration (Ballantyne, Michaelson, and Heggie 1938). The vessel wall spasm-proliferation relationship shown in this case is of

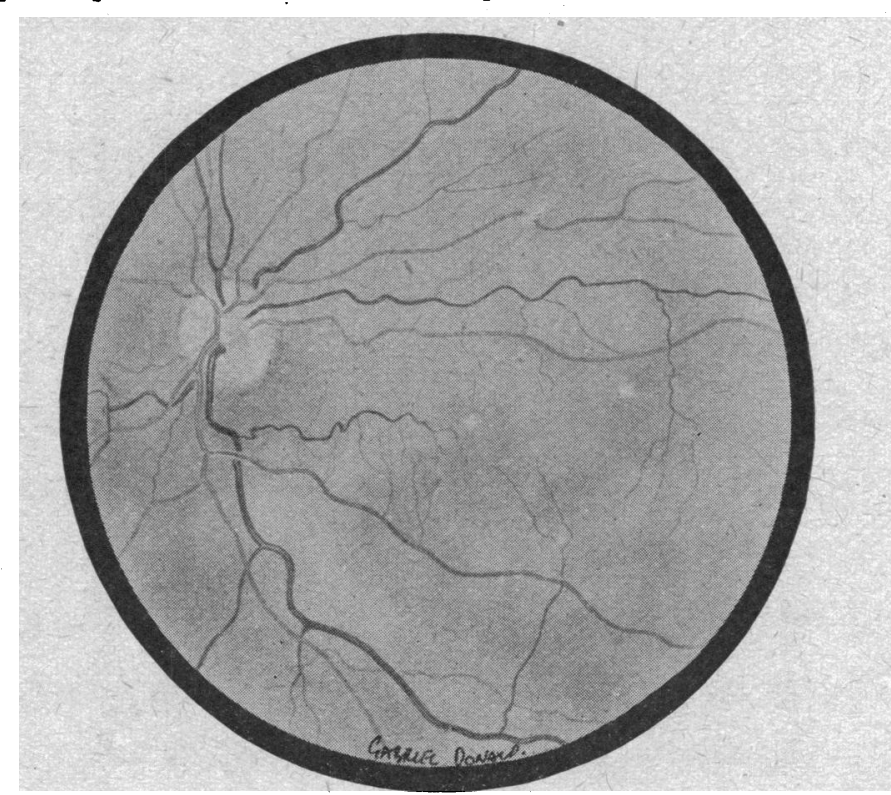

FIG. 3.

Appearance of fundus 43 days after onset of occlusion. At the site of spasm there is well-marked parallel sheathing of the vessel.

interest because it possibly illustrates in miniature a course of events, less acute but more diffuse, which may occur during the evolution of the general vascular changes of hypertension.

The beneficial effect of acetyl-choline on arterial occlusion due to spasm has already been noted by several observers. There is little doubt that acetyl-choline in this case relieved the spasm and restored the circulation. It is of interest there was no notable change in the diameter of the other retinal vessels following the injection, although search was repeatedly made. This lack of general response in the retinal vessels has been noted in two other patients treated with this drug. The localised effect of the drug on the spastic portion of one 
vessel in the fundus and the absence of response by healthy retinal vessels appear to invalidate any conclusions regarding the efficacy of acetyl-choline in spastic occlusion which may be made from the negative findings of experiments on animals which have normal retinal arteries.

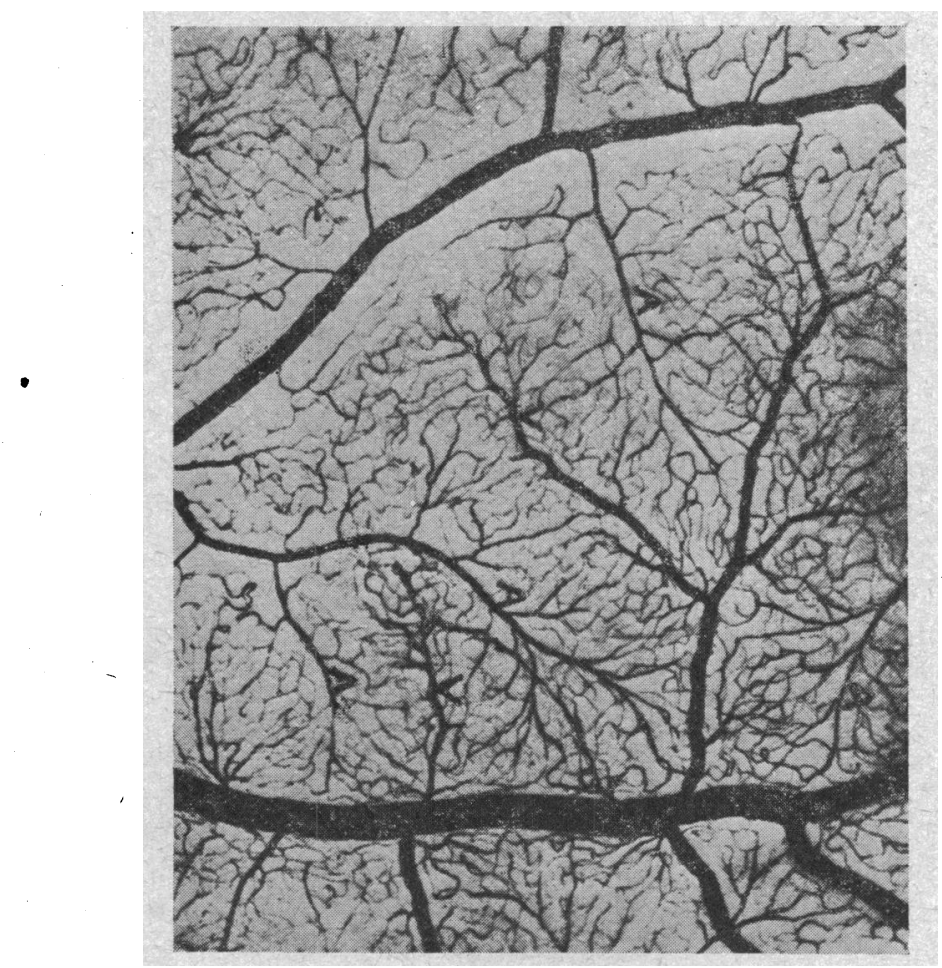

FIG. 4.

Portion of an injected human retina with artery above and vein below, selected as representing the triangular area of the capillary bed lying between the affected artery and the inferior temporal vein in the case described and because here likewise the ultimate arterial divisions (A) do not cross the vein.

The rapid disappearance of the white opacity suggests that it was due to oedema consequent on capillary stasis and anoxaemia resulting from diminished arterial inflow. Dunn (1940) has noted "that where an arterial supply is abnormally narrowed but not completely cut off, blood still passes to the vessel's natural territory under pressure at a less minute volume, and capillary engorgement in the area may be determined by this flow from the narrowed vessel itself even if there are no collateral anastomoses." During the 
period of spasm the affected artery beyond the occlusion was filled to its normal width with venous blood (Fig. 1), and it would seem that de-oxygenated blood in the dilated capillary plexuses has found it possible to pass into the artery "below" the constriction because of the diminished pressure within it. The artery is occluded at a place where it crosses a fork formed by two veins and, as can be seen from Fig. 3, no branch from the affected vessel crosses either of these veins. Fig. 4 from an injected human retina illustrates the manner by which under these circumstances, the capillary territory served by the artery is limited by the neighbouring vein; and in the case under consideration the constituent veins of the fork. As a consequence the oedema arising from the capillary disturbance is exactly limited by the veins above and below the artery as illustrated in Fig. 1.

\section{Summary}

(1). A case of retinal arterial occlusion is described in which the cause was arterial spasm.

(2). The spasm continued for 6 days and was overcome with acetyl-choline.

(3). Localised sheathing of the vessel wall resulted from the spasm and was detected 13 days after the onset of occlusion.

(4). Acetyl-choline does not appear to affect noticeably the diameter of healthy retinal vessels in man.

(5). The white retinal opacity was due to oedema.

(6). The disposition of retinal capillaries determined the extent of the retinal opacity.

I am indebted to $\mathrm{Mr}$. Gabriel Donald for his care with the illustrations.

\section{REFERENCES}

Ballantyne, Michaelson and Heggie.-Tians. Ophthal. Soc, U.K., Vol. LXVIII (1), p. 255, 1938.

Daven PORT.- Trans. Ophthal. Soc. U.K., Vol. LI, p. 115, 1931.

DunN, J. S.-Glasgow Med.Jl., p. 132, 1940.

FREEMAN.-Amer. Jl. Ophthal., Vol. XVI, p. 341, 1933.

GRIFFITH.-Trans. Ophthal. Soc. U.K., Vol. LI, p. 122, 1931.

MYLIUS.-Zeitschr. f. Augenheilk., Abhard, Vol. X, p. I, 1928.

ORMOND.-Brit. Jl. Ophthal., Vol. II, p, 273, 1918.

Schousboe.-Buil. Soc. d'Ophtal., Paris,Vol. XLIX, p. 112, 1937.

SEDAN.-Ann. d'Ocul., Vol. CLXVI, p. 705, 1929.

Selinger.-Amer. Jl. Ophthal., Vol. XX, p. 56, 1937.

TraguaIr. - Trans. Ophthal. Soc. U.K., Vol. LIII, p. 118, 1933. 